\title{
Otology
}

\section{Balloon dilation of the Eustachian tube: clinical experience in the management of 126 children}

\author{
Dilatazione tubarica con balloon: nostra esperienza nella gestione di 126 bambini \\ M. TISCH, H. MAIER, H. SUDHOFF \\ Department of Otolaryngology, Head and Neck Surgery, German Armed Forces Hospital of Ulm, Germany; \\ Department of Otolaryngology, Head and Neck Surgery, Bielefeld Academic Teaching Hospital, Bielefeld, Germany
}

\section{SUMMARY}

Balloon dilation of the Eustachian tube has been recently introduced as a novel and minimally invasive method for treating chronic obstructive Eustachian tube dysfunction. For the first time worldwide, we assessed the role of this technique in the treatment of children with Eustachian tube dysfunction who did not respond to other treatments. We retrospectively analysed the medical records of 60 children (mean age: 6.3 years, range: 28 months to 12 years) who underwent balloon dilation of the Eustachian tube using the Bielefeld balloon catheter. In addition, the parents of a further 66 children who underwent balloon dilation (mean age: 8 years, range: 4 to 13 years) were asked to complete a standardised written questionnaire and were interviewed by telephone about the postoperative course of their children. There were no complications during surgery. Clinical symptoms improved in more than $80 \%$ of patients. No patient reported a deterioration of symptoms. Of the participating parents, $81.3 \%$ were very satisfied or satisfied with the outcome of treatment. Balloon dilation is a rapid, simple and safe method for the treatment of both adults and children with Eustachian tube dysfunction that does not respond to other treatments. Further studies, ideally multicentre studies, are required in order to optimise the definition of existing and potential new indications for this treatment approach and to establish this treatment in the management of children with refractory chronic Eustachian tube dysfunction.

KEY WORDS: Eustachian tube $\bullet$ Eustachian tube dysfunction • Balloon dilation • Children

\section{RIASSUNTO}

La dilatazione tubarica con balloon è stata recentemente annoverata com nuovo metodo minimamente invasive per il trattmento della disfunzione cronica ostruttiva della tuba di Eustachio. Per la prima volta nel mondo, abbiamo definito il ruolo della suddetta tecnica nel trattamento della disfunzione tubarica cronica non rispondente ad altri trattamenti. Sono stati analizzati i dati clinici di 60 bambini (età media: 6,3 anni; range: da 28 mesi a 12 anni) sottoposti a dilatazione della Tuba di Eustachio con il balloon di Bielefeld. In aggiunta, sono stati reclutati i genitori di altri 66 bambini sottoposti a dilatazione con balloon, ed è stato chiesto loro di compilare un questionario standardizzato, e di rispondere ad alcune domande riguardo il decorso postoperatorio dei loro bambini. Non ci sono state complicanze durante gli interventi chirurgici. I sintomi clinici sono migliorati in più dell' $80 \%$ dei casi. Nessun paziente ha riferito un peggioramento sintomatologico. L'83\% dei partecipanti è rimasto notevolmente soddisfatto dei risultati derivanti dal trattamento. La dilatazione con balloon è una tecnica semplice, rapida e sicura per il trattamento della disfunzione tubarica non rispondente ad altri trattamenti sia negli adulti, sia nei bambini. Ulteriori studi, preferibilmente multicentrici, sarebbero utili per definire al meglio le indicazioni già esistenti e potenziali nuovi indicazioni per questa tipologia di trattamento, e per stabilire definitivamente il ruolo di questa tecnica nella gestione della disfunzione tubarica cronica refrattaria.

PAROLE CHIAVE: Tuba di Eustachio $\bullet$ Disfunzione tubarica $\bullet$ Dilatazione con balloon $\bullet$ Bambini

Acta Otorhinolaryngol Ital 2017;37:509-512

\section{Introduction}

Balloon dilation of the Eustachian tube has been recently introduced as a novel and minimally invasive method for treating chronic obstructive Eustachian tube dysfunction ${ }^{1-3}$. Success rates of $63 \%$ to $92.3 \%$ have been reported in studies with follow-up periods from 3 to 12 months ${ }^{1-4}$. Although children are most commonly affected by Eustachian tube dysfunction, balloon dilation was initially used only in adult patients because it was believed that the design of commercially available balloon catheters did not meet the specific anatomical conditions of the Eustachian tube in children. On closer examination, however, this argument was unconvincing. In 2010, the Department of Otolaryngology at the German Armed Forces Hospital of Ulm therefore used balloon dilation for the first time worldwide in the management of children with chronic obstructive tube dysfunction ${ }^{5}$.

More than 250 children with refractory chronic Eustachian tube dysfunction have now undergone this treatment in our department. 
In this article, we retrospectively analyse our patient population and present two cases in order to illustrate our treatment approach and first results.

\section{Materials and methods}

\section{Patients}

In a retrospective analysis, 60 children (first group of patients) were identified who underwent balloon dilation of the Eustachian tube for refractory chronic Eustachian tube dysfunction at the Department of Otolaryngology of the German Armed Forces Hospital in Ulm from October 2010 to December 2012.

In addition, the parents of a further 66 children (second group of patients) who underwent treatment between December 2012 and October 2013 were asked to complete a standardised written questionnaire (Fig. 1) and were interviewed by telephone about the postoperative course of their children.

The study was approved by the ethics committee of the University of Ulm.

\section{Diagnostic assessment and treatment}

Data on preoperative diagnostic procedures, previous treatment, surgical intervention, and postoperative course were obtained and documented from medical records of the first group of patients.

The parents of the patients from the second group were asked to complete a written questionnaire and were interviewed by telephone about the postoperative course of their children and about their satisfaction with out-

1. When was balloon dilation performed?

2. How many middle ear infections has your child had since balloon dilation of the Eustachian tube was performed?

3. How many times has your child required antibiotic treatment?

4. How many times has your child had otitis media with effusion?

5. How many times has your child undergone myringotomy or tympanostomy tube placement since balloon dilation of the Eustachian tube was performed?

6. Has your child's hearing improved after balloon dilation?

7. Has your child had any problems after balloon dilation? Yes/no

If yes, what problems?

Severe - moderate - mild

8. How satisfied are you with the treatment result? Very satisfied - satisfied - fairly satisfied - not satisfied

Fig. 1. Parent questionnaire. come. Indications for balloon dilation were the presence of chronic obstructive Eustachian tube dysfunction that was not managed satisfactorily with medical treatments (i.e. anti-inflammatory agents, decongestants, anti-allergic agents, autoinflation) and surgical treatments (i.e. adenoidectomy, turbinoplasty, myringotomy and tympanostomy tube placement).

Eustachian tube function was assessed on the basis of the following tests:

- Valsalva maneuver and Toynbee test (if possible).

- Tympanogram (intact tympanic membrane).

- Otomicroscopy.

These examinations were performed before surgery and at 6 to 8 weeks after surgery.

\section{Balloon dilation}

We used a modification of the technique that was originally described by Sudhoff et al. ${ }^{36}$. Laryngeal mask airways were generally used during anaesthesia. A xylometazoline solution was used for nasal decongestion. A $30^{\circ}$ Hopkins rod was then inserted on the side to be treated. An insertion instrument was carefully introduced on the contralateral side. A balloon catheter was passed through the insertion instrument and pushed $2 \mathrm{~cm}$ into the Eustachian tube under endoscopic vision. The balloon was inflated to a pressure of $10 \mathrm{bar}$ for $2 \mathrm{~min}$. Routine postoperative care consisted of the application of nasal drops containing xylometazoline and panthenol ointment for three days. Some patients also received antihistamines or topical corticosteroids. Starting on the third day following surgery, patients were instructed, if possible, to autoinflate the Eustachian tube by performing Valsalva maneuvers or using the Otovent device.

\section{Results}

The patient group that was investigated in the first part of the study consisted of 60 children with a mean age of 6.3 years and a range from 28 months to 12 years. Of these patients, 20 had undergone at least one previous tympanoplasty. The mean follow-up was 13 months.

Before surgery, $91.6 \%$ of the children were unable to equalise middle ear pressure, as indicated by the absence of a positive Valsalva test on microscopy or the absence of a definable peak on a tympanogram ("flat" tympanogram). Complete adhesion was observed in 22 children (37\%). Preoperative computed tomography (CT) scans were obtained from 28 patients with chronic otitis media and suspected cholesteatoma. The other 32 children did not undergo computed tomography of the petrous portion of the temporal bone before surgical intervention.

A total of 30 unilateral and 30 bilateral dilations were performed.

There were no complications during surgery. Immediately after surgery, one patient (1\%) had a nose bleed, which 
was easily managed with bipolar coagulation and anterior nasal packing.

No further treatment-associated complications were reported.

After surgery, only 11 children (18.3\%) were objectively unable to equalise middle ear pressure, as indicated by the absence of a positive Valsalva test on microscopy or the absence of a definable peak on a tympanogram. In 18 of the 22 patients, adhesions had been separated so that there was no further contact between the tympanic membrane and the promontory or between the tympanic membrane and the long process of the incus.

Of the 66 parents who were contacted during the second part of the study, $34(51.5 \%)$ agreed to take part. The mean age of the children in this group was 8 years with a range from 4 to 13 years. The mean follow-up period was 9.5 months.

Hearing improved in $76.5 \%$ of children. Of the participating parents, $55.9 \%$ were very satisfied and $25.4 \%$ were satisfied with the results of surgery. The parents of only one child stated that they were not satisfied with the outcome. No serious complications following balloon dilation were reported. Immediately after the procedure, one child experienced mild epistaxis. Another child had postoperative pain. Three children developed otitis media in the days following balloon dilation. In the further postoperative course, otitis media with effusion occurred in three cases. Balloon dilation of the Eustachian tube had to be repeated in 9 of the 34 patients.

\section{Discussion}

Obstructive Eustachian tube dysfunction is most commonly seen in children. It is currently assumed that at least $80 \%$ of all preschool children are affected at least temporarily by this condition. The greater predisposition of children for Eustachian tube dysfunction can be primarily explained by the anatomy of the Eustachian tube in children ${ }^{7}$.

1. The tube is considerably shorter in infants and young children than in older children or adults. This impairs the protective function of the middle ear system.

2. In young children, the Eustachian tube lies at a relatively flat angle in relation to the horizontal plane, which adversely affects the role of the tensor veli palatini muscle in opening the tube. This can lead to limited ventilation of the middle ear during upper respiratory tract infections.

3. The mass of Ostmann's fat pad is relatively greater in children than in adults. This limits the opening of the tubal lumen when the tensor veli palatini muscle contracts.

4. There are considerable differences in cartilage structure between children and adults. Cartilage in children has less volume and is softer. In addition, the elastin in the cartilage is less dense and cartilage cell density is greater in young children. This results in a lack of stiffness, increased compliance, and limited efficiency of the opening mechanism of the Eustachian tube.

5. Moreover, the mucous membrane of the cartilaginous portion of the Eustachian tube is thicker and contains more folds in children. It is possible that this tissue, which is known as the tubal tonsil, quickly reacts with inflammatory responses to exposure to microbial agents and allergens.

As a result, post-inflammatory adhesions are likely to occur in this region of the Eustachian tube and impair tubal opening. Sheer et al. ${ }^{8}$ developed finite element models of Eustachian tube function and found that compliance of the periluminal mucosa was a significant predictor of the effectiveness of the tensor veli palatini muscle.

Differential diagnosis includes a variety of conditions that can contribute to the development of obstructive Eustachian tube dysfunction in children. The first to be mentioned is adenoid hyperplasia. Other conditions that can play a causative role are acute and chronic infections, allergic disease, hyperplasia of the nasal conchae, immune defects, impairments in ciliary function and reflux.

Initial treatment should generally focus on the management of the aforementioned causes or contributors.

Until recently, the options available for restoring middle ear aeration have been limited when treatments fail and chronic obstructive Eustachian tube dysfunction develops. Apart from pressure equalization manoeuvers (e.g. Valsalva, Otovent), repeated myringotomies and tympanostomy tube insertions were the only possible treatment modalities.

With the advent of balloon dilation, a novel and minimally invasive method for treating chronic obstructive Eustachian tube dysfunction has been established and successfully used for the management of adult patients in recent years ${ }^{1-4} 9$.

The results of the present study suggest that children appear to benefit from this intervention in a similar fashion. When all established treatment modalities were unsuccessful in an 18-month-old girl, we decided to perform balloon dilation of the Eustachian tube for the first time in a young child. The excellent treatment result encouraged us to use this technique in an increasing number of children at our department. This decision is supported by an analysis of the treatment results we obtained for 60 children with complex and chronic obstructive Eustachian tube dysfunction that was unresponsive to other treatments. The percentage of children who were unable to equalise middle ear pressure decreased from $91.6 \%$ of the children before balloon dilation to $18.3 \%$ after the intervention. In 18 of 22 children (81.8\%), we were even able to successfully separate adhesions.

These positive findings are all the more remarkable as the method is minimally invasive and causes only mild dis- 
comfort. No patient experienced serious complications. The parents' evaluation of the treatment results, too, is convincing. With a percentage as high as $81.3 \%$, the vast majority of participating parents were very satisfied or satisfied with the outcome of balloon dilation.

The reasons why balloon dilation was not recommended for children until recently are difficult to understand. A major concern was that the procedure could be associated with serious complications such as the risk of injury to the internal carotid artery, especially when the artery follows an aberrant course in the osseous region of the Eustachian tube or when there is a dehiscence of the bony carotid canal. Such concerns had been expressed even before the technique was used in the treatment of adults and were raised even more when the use of balloon dilation was considered in children who have thinner and more vulnerable vessel walls. This argument would be understandable if the osseous portion of the Eustachian tube were dilated, as some authors mistakenly believed in the past. It is, however, not the osseous portion but the cartilaginous portion of the Eustachian tube that is dilated and which is located at a safe distance from the carotid canal. This is one of the reasons why we do not necessarily obtain preoperative CT scans of the skull in all cases, as demanded by some authors ${ }^{4}$. Other critics of the use of balloon dilation in children argue that the balloon length $(20 \mathrm{~mm})$ of commercially available catheters makes these devices unsuitable in children for anatomical reasons. In our opinion, this argument is also unconvincing. The Eustachian tube lengthens during childhood and by 7 years of age is approximately as long as in adults. Although the tube is shorter in young children, the ratio of the length of the cartilaginous portion to the osseous portion is $8: 1$ in the infant compared to $4: 1$ in the adult. As a result, the length of the balloon appears not to be a critical factor in the risk of placing the balloon in the osseous portion instead of the cartilaginous portion of the Eustachian tube. Moreover, catheters with a balloon length of $1.5 \mathrm{~cm}$ or $1.0 \mathrm{~cm}$ are today available.

There is still some controversy regarding the mechanism of action of balloon dilation. A possible explanation is that microruptures in the region of the tubal cartilage lead to a permanent widening of the cartilaginous Eustachian tube ${ }^{1011}$. Another possible explanation is that the stimulation of proprioceptors may influence the tensor veli palatini and levator veli palatini muscles ${ }^{11}$. Apart from these possible explanations, we have established the hypothesis that dilation can separate scars or adhesions of the folded mucosa of the Eustachian tube, which can develop after inflammation.

\section{Conclusions}

In our opinion, balloon dilation of the Eustachian tube is a safe and reliable alternative in the management of adults and especially children with chronic Eustachian tube dysfunction that does not respond to conservative/established therapies.

\section{References}

1 Poe D. In reference to Balloon dilatation Eustachian tuboplasty: a clinical study. Laryngoscope 2011;121:908.

2 Poe DS, Hanna BM. Balloon dilation of the cartilaginous portion of the eustachian tube: initial safety and feasibility analysis in a cadaver model. Am J Otolaryngol 2011;32:115-23.

3 Schröder S, Reineke U, Lehmann M, et al. Chronic obstructive Eustachian tube dysfunction in adults: long-term results of balloon Eustachian tuboplasty. HNO 2013; 61:142-51.

4 Tisch M, Maier S, Maier H. Eustachian tube dilation using the Bielefeld balloon catheter: clinical experience with 320 interventions. HNO 2013;61:483-7.

5 Tisch M, Maier S, Hecht P, et al. Bilateral Eustachian tube dilation in infants: an alternative treatment for persistent middle ear functional dysfunction. HNO 2013;61:492-3.

6 Sudhoff H, Ockermann T, Mikolajczyk R, et al. [Clinical and experimental considerations for evaluation of Eustachian tube physiology]. HNO 2009;57:428-35.

7 Bluestone CD, Doyle WJ. Anatomy and physiology of eustachian tube and middle ear related to otitis media. J Allergy Clin Immunol 1988;81:997-1003.

8 Sheer FJ, Swarts JD, Ghadiali SN. Three-dimensional finite element analysis of Eustachian tube function under normal and pathological conditions. Med Eng Phys 2012;34:605-16.

9 Jurkiewicz D, Bień D, Szczygielski K, et al. Clinical evaluation of balloon dilation Eustachian tuboplasty in the Eustachian tube dysfunction. Eur Arch Otorhinolaryngol 2013;270:1157-60.

10 Ockermann T, Reineke U, Upile T, et al. Balloon dilation eustachian tuboplasty: a feasibility study. Otol Neurotol 2010; 31:1100-3.

11 Ockermann T, Reineke U, Upile T, et al. Balloon dilatation eustachian tuboplasty: a clinical study. Laryngoscope 2010;120:1411-6. 